\title{
MOLECULAR ASPECTS OF NON-INSULIN-DEPENDENT DIABETES
}

\author{
STEPHEN O'RAHILLY \\ Cambridge
}

The last five years have been an exciting time for those interested in understanding the fundamental aetio-pathogenesis of non-insulin-dependent (type 2) diabetes mellitus (NIDDM). Studies have begun to move from examination of gross alterations in whole-body metabolism to the investigation of specific molecules central to both insulin secretion and action (Fig. 1). NIDDM has always been suspected to be a highly heterogeneous grouping of syndromes and the recent discovery of individuals whose hyperglycaemia is due to specific mutations in the insulin gene, the insulin receptor gene and glucokinase gene, has confirmed that this is the case. The extent to which inherited defects in these genes contribute to NIDDM as a whole is still open to question. It has long been assumed that two major factors contribute to the development of NIDDM: an ill-defined inherited component which is reflected in the high concordance in identical twins ${ }^{1}$ and the environmentally induced obesity and inactivity occurring in 'Western-style' cultures. ${ }^{2}$ Recent data concerning the relationship between birth weight and later development of diabetes have led to the suggestion that the intra-uterine environment may also have a major influence on susceptibility to NIDDM many years later. ${ }^{3}$

Whether the basic problem is inherited or environmental (and in the latter case whether pre- or post-natal) the disorder of NIDDM ultimately expresses itself by a combination of defects: the beta cell does not secrete insulin normally and insulin-sensitive tissues (liver, fat and muscle) fail to respond to insulin adequately. ${ }^{4}$ Enormous strides have been made in the understanding of the basic mechanisms of insulin secretion and action. I shall briefly describe the function of some of the key molecules in both these processes and in each case summarise the evidence that inherited or acquired abnormalities of these molecules may contribute to NIDDM.

\section{THE BETA CELL}

\section{Normal Physiology}

The question of how the normal beta cell senses and

Correspondence to: Dr. Stephen O'Rahilly, Department of Medicine, Addenbrooke's Hospital, Hills Road, Cambridge CB2 2QQ, UK. responds to plasma glucose with unerring accuracy has been a much-investigated question (Fig 2). A major advance in understanding was the discovery that the beta cell has a specific glucose transporter (GLUT2: which it shares with the liver) in its cell membrane, the transport kinetics of which are such that intracellular glucose concentrations parallel extracellular concentrations. ${ }^{5}$ Coupled with this was the finding that the beta cell phosphorylates its glucose to glucose-6-phosphate using glucokinase, an enzyme which has a high Michaelis constant $\left(K_{\mathrm{m}}\right)$ and is not subject to product inhibition. ${ }^{6}$ This combination of GLUT2 and glucokinase ensures that the amount of glucose-6-phosphate available for glycolysis and generation of ATP is directly proportional to plasma glucose. The ATP generated during glycolysis (in the cytosol) and oxidative phosphorylation (in the mitochondria) is responsible for the closing of an ATP-sensitive potassium channel in the plasma membrane. This causes depolarisation of the cell and opening of a voltage-sensitive calcium channel. ${ }^{7}$ The influx of calcium leads to exocytosis of secretory granules containing insulin. Investigation of the constituents of the secretory granule has revealed the presence of several other peptides and neurotramsmitters, in particular islet amyloid polypeptide (IAPP) or amylin, ${ }^{8}$ which will be discussed further below.

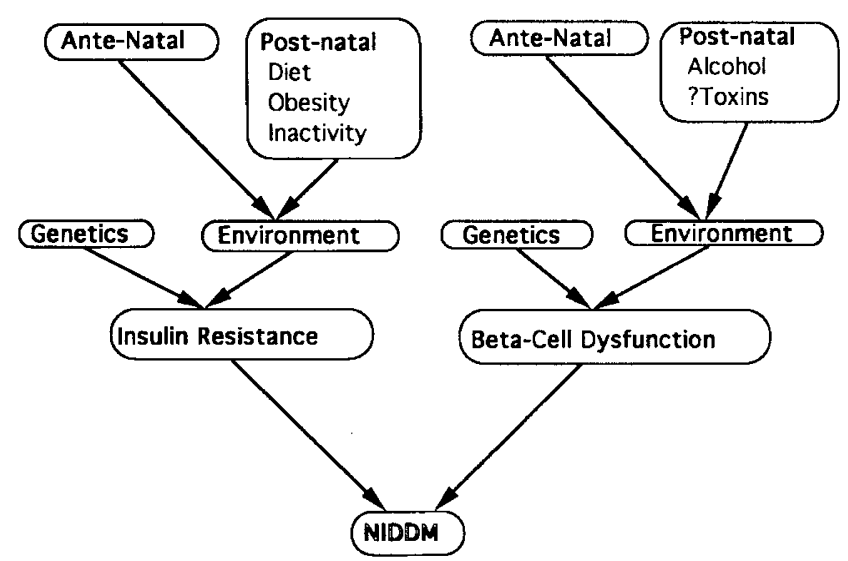

Fig. 1. An overview of the genetic and environmental influences on the development of NIDDM. 


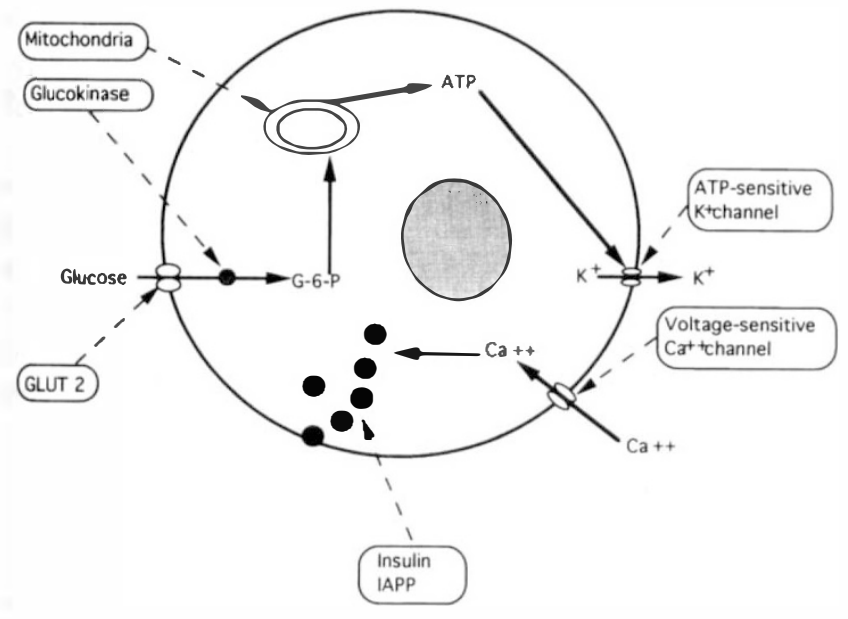

Fig. 2. Some critical steps in the beta cell secretory response to glucose. See text for detailed description.

Clinical investigators have exploited these fundamental discoveries and examined the role of inherited or acquired defects in many of these molecules in the aetiology of NIDDM.

\section{GLUT2 Gene}

The GLUT2 gene has been studied in families with earlyonset forms of NIDDM and no linkage has been found between the gene and the disease. ' Likewise in 'common' NIDDM there is little convincing evidence of any genetic association. Studies of GLUT2 expression in islets in animal models of diabetes have, however, suggested an important role for this transporter in the mediation of the phenomenon of 'glucose toxicity'. It has long been recognised clinically that diabetes tends to be self-perpetuating and that if severe hyperglycaemia is treated there is often a striking recovery of insulin secretion. In various models of NIDDM Thorens and colleagues have clearly demonstrated that GLUT2 is down-regulated by hyperglycaemia and that this can be reversed by any treatment which restores the blood glucose to normal. ${ }^{10}$

\section{Glucokinase}

One of the most exciting recent findings in NIDDM has been the demonstration that a substantial number of families with an early-onset, relatively mild, autosomal dominant form of diabetes (sometimes termed maturity onset diabetes of the young: MODY) show close linkage of their disorder with the glucokinase gene. ${ }^{11,12}$ Several point mutations have now been found in this gene which lead directly to diabetes. ${ }^{13}$ Phenotypic studies of these patients clearly show that their diabetes is due to a defective insulin secretory response and this presumably reflects a pure 'glucose-sensing' defect in the beta cell. The definition of such a defect, for the first time, allows rationally based therapy for a subset of patients with NIDDM. As the defect in these patients is early in the metabolism of glucose and the generation of ATP, sulphonylureas, which act on the ATP-sensitive potassium channel, should be able to bypass this defect and allow normal insulin secretion from normal secretory granules. The extent to which mutant glucokinase genes contribute to the broader spectrum of patients with NIDDM remains open to question. It should be noted, however, that many of the patients in the MODY pedigrees were not diagnosed until middle age, and had been clinically classified as conventional NIDDM patients.

\section{Mitochondrial Genome}

As the mitochondria are the major site of ATP generation, and ATP is a critical signal for insulin secretion, it might perhaps be expected that defects in the mitochondrial oxidative phosphorylation complex would be associated with defective insulin secretion. Recently, families have been described in which deafness and NIDDM are due to defects of the mitochondrial genome. ${ }^{14}$ As the mitochondrial genome is maternally inherited it is interesting to note that several studies of NIDDM have recognised a predominance of maternal inheritance. It is premature to assume that the diabetes in these families is due to a defect of mitochondrial metabolism in the beta cell alone as the relevant pathophysiological studies have not been performed and it is possible that insulin action is also affected.

\section{Insulin}

The insulin molecule itself is normal in the vast majority of patients with NIDDM but a small number of subjects have been reported to have mutant insulins. ${ }^{15}$ Such patients may or may not be hyperglycaemic. Of more relevance to NIDDM is the realisation that the disordered beta cell in NIDDM releases an excess of imperfectly processed insulin precursors so that as much as $50 \%$ of the insulin measured by radio-immunoassay in the plasma of a patient with NIDDM may actually represent processing intermediates of much lower biological activity. ${ }^{16}$

\section{Islet Amyloid Polypeptide (Amylin)}

At post-mortem the majority of patients with NIDDM have been shown to have amorphous material in the islets which has the staining characteristics of amyloid. ${ }^{17}$ The long-standing and surprising neglect of this provocative observation is probably due to the fact that this amyloid material was also found in some normals and was dismissed as a non-specific feature of ageing. Careful histopathological studies by Clark and others re-established the close relationship of amyloid and diabetes. ${ }^{18}$ It is notable that in the species in which NIDDM is associated with pancreatic amyloid (humans, cats, racoons) the normal IAPP molecule is capable of forming amyloid fibrils, unlike that of species such as rats, mice and dogs whose NIDDM is not associated with amyloid deposits. ${ }^{19}$ The sequence of IAPP has been normal in all NIDDM subjects studied to date. ${ }^{20}$ It is possible, however, that a defect in its processing and/or clearance is of fundamental relevance to the development and progression of NIDDM.

\section{INSULIN-SENSITIVE TISSUE}

The attempt to reach a comprehensive understanding of 


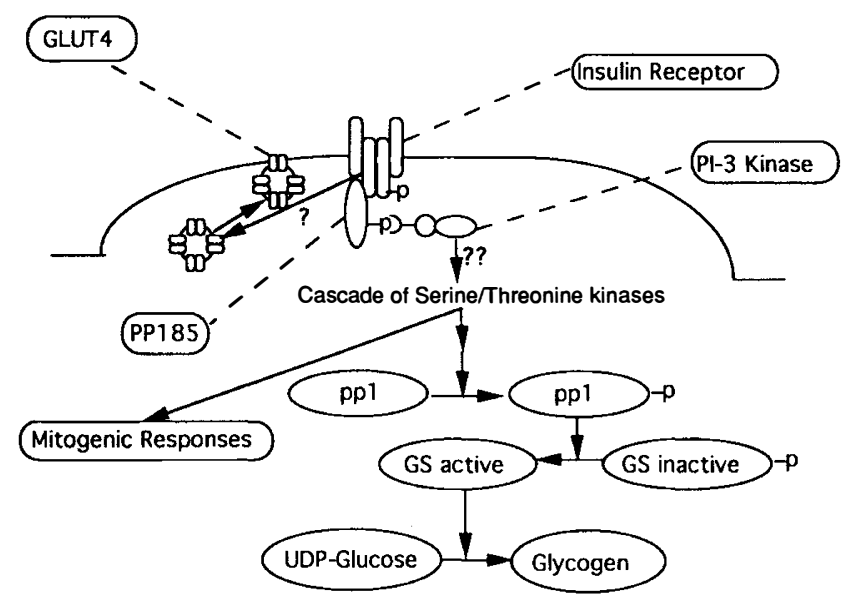

Fig. 3. A simplified overview of insulin action. See text for further details.

the actions of insulin at the molecular level has proved to be a difficult and demanding task (Fig. 3). This relates to the multiplicity of actions of insulin on carbohydrate, lipid and protein metabolism and the tissue-specific nature of some of its effects. Considerable advances have been made in the understanding of the proximal and distal ends of several of insulin's signalling pathways, but gaps remain in our understanding of the signalling intermediates. Insulin mediates essentially all its effects by binding to the insulin receptor, a dimeric cell surface molecule the intracellular beta subunits of which become rapidly phosphorylated on specific tyrosine residues upon binding of insulin. This phosphorylation activates the ability of the insulin receptor itself to phosphorylate other intracellular proteins. ${ }^{21}$ One of these proteins (IRS-1) has recently been cloned and, although it does not appear to have any kinase activity itself, its phosphorylation may allow docking of one or more kinases which initiate signalling cascades involving serine and threonine kinases. ${ }^{22}$ Taking glycogen synthesis as the distal step in one of insulin's main effects on glucose metabolism, major advances have been made in the understanding of the elegant kinase/phosphatase interactions which allow the stimulation of glycogen synthase and the inhibition of phosphorylase by insulin to occur. ${ }^{23}$ The precise links between the proximal and distal elements of this signalling pathway are the subject of intensive investigation.

The stimulation of glucose transport by insulin in muscle and fat involves the translocation of a specific glucose transporter (GLUT4) from intracellular vesicles to the plasma membrane. ${ }^{24}$ It is unclear whether the kinase cascade initiated by insulin is of direct relevance to this pathway or whether alternative insulin-receptor-generated signals are involved. I will restrict my discussion of the clinically relevant molecules to the insulin receptor and GLUT4.

\section{Insulin Receptor}

In 1988 Kadowaki et al. described the first patient with a mutant insulin receptor. This was a baby with extreme insulin resistance and the 'leprechaunism' phenotype. ${ }^{25}$ It is now clear that leprechaunism represents one end of a spectrum of 'inherited insulin receptoropathies.' Mutations with less severe consequences for function are found in children with the Rabson-Mendehall syndrome. ${ }^{26} \mathrm{Sev}-$ eral adolescent females whose insulin resistance has led to ovarian hyperandrogenism (type A insulin resistance) have been found to be heterozygous for point mutations in the tyrosine kinase domain. ${ }^{27}$ Such mutations in a single allele have surprisingly severe consequences which can be explained by the inhibitory effect of the mutations on receptors where they are only present in one of the two beta subunits. This results in $75 \%$ of cellular receptors being defective (25\% mutant dimers and 50\% mutant/ wild-type dimers) - the so-called dominant-negative effect. The contribution of insulin receptor mutations to common NIDDM has been investigated by ourselves and others and mutations of the insulin receptor have not been frequently found. ${ }^{28,29}$ However, we and others have found heterozygous relatives of patients with severe homozygous insulin resistance who themselves have no clinical phenotype other than glucose intolerance/NIDDM and hyperinsulinaemia (unpublished observations). ${ }^{30}$ Thus it is likely that among the heterogeneous population of NIDDM patients there will be subjects in whom insulin receptor mutations are contributing to their disease. On the other hand, acquired defects of the insulin receptor kinase activity have been widely reported in subjects with NIDDM. ${ }^{31}$ The mechanism whereby the diabetic state affects the function of the insulin receptor is unknown.

\section{Insulin-Responsive Glucose Transporter}

Unlike the insulin receptor, no pathogenic human mutations of GLUT4 have, to date, been found, although one variant sequence has been reported.$^{32}$ In animal models of NIDDM, GLUT4 expression is reduced, particularly in adipose tissue and to a lesser extent in muscle. ${ }^{33}$ Studies of muscle and fat tissue in patients with NIDDM have failed to detect any consistent reduction in expression at either the protein or mRNA level.

\section{CONCLUSION}

There can be no doubt that the discoveries mentioned in this brief review represent only the beginning of understanding of the precise molecular alterations which can lead to the diabetic state. It is to be hoped that further advances in these fields will lead to more precise classification with ultimate implications for prognosis, treatment and prevention of NIDDM.

Key words: Diabetes, Genetics, Insulin action, Insulin secretion.

\section{REFERENCES}

1. Barnett AH, Eff C, Leslie RDG, Pyke DA. Diabetes in identical twins: a study of 200 pairs. Diabetologia 1981;20: 87-93.

2. Zimmet P. Type 2 (non-insulin-dependent) diabetes: an epidemiological overview. Diabetologia 1982;22:399-411.

3. Hales CN, Barker DJP. Type 2 (non-insulin dependent) diabetes mellitus: the thrifty phenotype hypothesis. Diabetologia 1992;35:595-601. 
4. Cahill GF Jr. Beta cell deficiency, insulin resistance, or both? N Engl J Med 1988;318:1268-9.

5. Permutt MA, Koranyi L, Keller K, Lacey PE, Scharp DW, Mueckler M. Cloning and functional expression of a human pancreatic islet glucose-transporter cDNA. Proc Natl Acad Sci USA 1989;86:8688-92.

6. Magnuson MA. Perspectives in diabetes. Glucokinase gene structure: functional implications of molecular genetic studies. Diabetes 1990;39:523-7.

7. Rajan AS, Aguilar-Bryan L, Nelson DA, Yaney GC, Hsu WH, Kunze DL, Boyd AE. Ion channels and insulin secretion. Diabetes Care 1990;13:340-63.

8. Cooper GJ, Willis AC, Clark A, Turner FC, Sim RB, Reid KB. Purification and characterisation of a peptide from amyloid-rich pancreases of type 2 diabetic patients. Proc Natl Acad Sci USA 1987;84:8628-32.

9. Patel P, Lo Y-MD, Hattersley A, Bell GI, Tybjaerg-Hansen A, Nerup $\mathrm{J}$ et al. Linkage analysis of maturity-onset diabetes of the young with microsatellite polymorphisms: no linkage to ADA or GLUT2 genes in two families. Diabetes 1992;41: 962-7.

10. Thorens B, Wu YJ, Leahy JL, Weir GC. The loss of GLUT2 expression by glucose-unresponsive beta-cells of $d b / d b$ mice is reversible and is induced by the diabetic environment source. J Clin Invest 1992;90:77-85.

11. Froguel P, Vaxillaire M, Sun F, Velho G, Zouali H, Butel MO et al. Close linkage of glucokinase locus on chromosome $7 \mathrm{p}$ to early-onset non-insulin dependent diabetes mellitus. Nature 1992;356:162-4.

12. Velho G, Froguel P, Clement K, Pueno ME, Rakotoambinina $\mathrm{B}$, Zouali $\mathrm{H}$ et al. Primary pancratic beta-cell secretory deficit caused by mutations in the glucokinase gene in kindreds of maturity-onset diabetes of the young. Lancet 1992; 340:444-8.

13. Stoffel M, Froguel P, Takeda J, Zouali H, Vionnet N, Nishi S et al. Human glucokinase gene: isolation, characterization and identification of two missense mutations linked to earlyonset non-insulin-dependent (type 2) diabetes mellitus. Proc Natl Acad Sci USA 1992;89:7698-702.

14. Scott WB, Shoffner JM, Hedaya EV, Trounce I, Meraida AP, Koontz DA, Wallace DC. Maternally transmitted diabetes and deafness associated with a $10.4 \mathrm{~kb}$ mitochondrial DNA deletion. Nature Gene 1992;1:11-5.

15. Barbetti F, Raben N, Kadowaki T, Cama A, Accili D, Gabbay KH et al. Two unrelated patients with familial hyperproinsulinemia due to a mutation substituting histidine for arginine at position 6 in the proinsulin molecule: identification of the mutation by direct sequencing of genomic deoxyribonucleic acid amplified by polymerase chain reaction. J Clin Endocrinol Metab 1990;71:164-9.

16. Temple RC, Carrington CA, Luzio SD, Owens DR, Schneider AE, Sobey WJ, Hales CN. Insulin deficiency in non-insulin-dependent diabetes. Lancet 1989;1:293-5.

17. Bell ET. Hyalinization of the islets of Langerhans in diabetes mellitus. Diabetes 1952;1:341-4.

18. Clark A, Holman RR, Matthews DR, Hockaday TD, Turner RC. Non-uniform distribution of islet amyloid in the pancreas of 'maturity-onset' diabetic patients. Diabetologia $1984 ; 27: 527-8$.

19. Johnson KH, O’Brien TD, Betsholtz C, Westermark P. Islet amyloid, islet-amyloid polypeptide, and diabetes mellitus. N Engl J Med 1989;321:513-8.

20. Nishi M, Bell GJ, Steiner DF. Islet amyloid polypeptide (amylin): no evidence of an abnormal precursor sequence in 25 type 2 (non-insulin-dependent) diabetic patients. Diabetologia 1990;33:628-30.

21. McClain DA. Insulin action in cells expressing truncated or kinase-defective insulin receptors: dissection of multiple hormone-signalling pathways. Diabetes Care 1990;13: 302-16.

22. Ullrich A, Bell JR, Chen EY, Herrera R, Petruzzelli LM, Dull TJ et al. Human insulin receptor and its relationship to the tyrosine kinase family of oncogenes. Nature 1985;313: 756-61.

23. Dent P, Lavoinne A, Nakielny S, Caudwell FB, Cohen P. The molecular mechanism by which insulin stimulates glycogen synthesis in mammalian skeletal muscle. Nature 1990;348:302.

24. James DE, Brown R, Navarro J, Pilch PF. Insulin-regulatable tissues express a unique insulin-sensitive glucose transport protein (letter). Nature 1988;333:183-5.

25. Kadowaki T, Bevins CL, Cama A, Ojamaa K, MarcusSamuels B, Kadowaki $\mathrm{H}$ et al. Two mutant alleles of the insulin receptor gene in a patient with extreme insulin resistance. Science 1988;240:787-90.

26. Kadowaki T, Kadowaki H, Rechler MM, Serrano-Rios M, Roth J, Gorden P, Taylor SI. Five mutant alleles of the insulin receptor gene in patients with genetic forms of insulin resistance. J Clin Invest 1990;86:254-64.

27. O'Rahilly S, Moller DE. Mutant insulin receptors in syndromes of insulin resistance. Clin Endocrinol 1992;36: 121-32.

28. O'Rahilly S, Choi WH, Patel P, Turner RC, Flier JS, Moller DE. Detection of mutations in the insulin receptor gene in non-insulin-dependent diabetic patients by analysis of single-stranded conformation polymorphisms. Diabetes 1991;40:777-82.

29. Kusari J, Verma US, Buse JB, Henry RR, Olefsky JM. Analysis of the gene sequences of the insulin receptor and the insulin-sensitive glucose transporter (GLUT4) in patients with common-type non-insulin-dependent diabetes mellitus. J Clin Invest 1991;88:1323-30.

30. Lekanne-Deprez RH, van Loon BJP, van der Zon GCM, Moller W, Lindout D, Klinkhamer MP et al. Individuals with only one allele for a functional insulin receptor have a tendency to hyperinsulinaemia but not hyperglycaemia. Diabetologia 1989;32:740-4.

31. Maegawa H, Shigeta Y, Egawa K, Kobayashi M. Impaired autophosphorylation of insulin receptors from abdominal skeletal muscles in non-obese subjects with NIDDM. Diabetes 1991;40:815-9.

32. Choi WH, O'Rahilly S, Rees A, Morgan R, Flier JS, Moller DE. Molecular scanning of the insulin responsive glucose transporter and insulin receptor genes. Diabetes 1991;40: 1712-18.

33. Garvey WT, Huecksteadt TP, Birnbaum MJ. Pretranslational suppression of an insulin-responsive glucose transporter in rats with diabetes mellitus. Science 1989;245: 60-3. 